\section{Expressão de glicoesfingolipídeos no carcinoma espinocelular do trato aerodigestivo superior}

Marcilio Ferreira Marques Filho ${ }^{1}$, Fernando Walder ${ }^{2}$, Helio K. Takahashi ${ }^{3}$, Luciana L. Guimarães ${ }^{4}$, Ameria K. Tanaka $^{5}$, Onivaldo Cervantes ${ }^{6}$, Anita H. Straus ${ }^{7}$

\section{Resumo}

$\mathrm{O}$ glicoesfingolipídios (GSLs) são importantes componentes da membrana celular, organizados em microdomínios, relacionados a receptores de membrana e comportamento anti-social da célula neoplásica como crescimento descontrolado, invasão e ocorrência de metástases. Objetivo: Como a expressão de GSLs no carcinoma espinocelular (CEC) é tema pouquíssimo estudado decidiu-se realizar estudo prospectivo visando avaliar a expressão de GSLs no CEC do trato aerodigestivo superior. Método: Coletou-se 33 amostras de CEC e mucosa normal e GSLs extraídos e purificados por cromatografia de fase reversa em coluna de C-18 e hidrólise alcalina em metanol. Os GSLs foram quantificados por densitometria das placas de cromatografia de alta resolução em camada delgada coradas com orcinol. Resultados: Observouse aumento significativo de GSLs no CEC $(3,57 \mu \mathrm{g} / \mathrm{mg})$ em comparação à mucosa normal $(1,92 \mu \mathrm{g} / \mathrm{mg})$, principalmente do monosialogangliosídeo (GM3), trihexosilceramida (CTH), dihexosilceramida (CDH), globosídeo (Gb4). A expressão de monohexosilceramida (CMH) foi semelhante no CEC e na mucosa normal. O aumento do GM3 no CEC foi demonstrado por métodos imunoquímicos empregando-se MAb DH2 (anti-GM3). Analisando-se os carboidratos do CMH por cromatografia gasosa acoplado a espectrômetro de massa constatou-se que a mucosa normal expressa glucosilceramida e o CEC glucosilceramida e galactosilceramida. Conclusão: O aumento de GSLs no tecido tumoral pode representar alterações dos microdomínios da membrana celular resultantes do processo de transformação maligna, responsáveis por uma maior interação célula-célula e célula-matriz aumentando seu potencial de infiltração e metástase, possibilitando o emprego dos GSLs e de MAbs no diagnóstico e no tratamento do CEC, a exemplo do que ocorre no melanoma.

\section{Glycosphingolipid expression in squamous cell carcinoma of the upper aerodigestive tract}

Palavras-chave: glicoesfingolipídios, carcinoma de células escamosas, gangliosídeos, neoplasias de cabeça e pescoço. Key words: glycosphingolipids, squamous cell carcinoma, gangliosides, head and neck neoplasms.

\section{/ Summary}

C

Jycosphingolipids are integral constituents of cellular membrane, arranged in rafts, and with neoplasic cell antisocial behavior, like uncontrolled cell growth, invasiveness, and metastatic potential. Aim: However, there are few studies about glycosphingolipids (GSL) expression in squamous cell carcinoma (SCC). Since GSL are known to be tumorassociated markers we decided to perform a prospective study on the GSL profiles of SCC. Method: Specimens of 33 SCC and normal mucosa were obtained and GSLs were extracted and purified by reverse-phase chromatography on C18 column and alkaline hydrolysis in methanol. GSLs were quantified using densitometry of orcinol-stained HPTLC plates. Result: A significant increase of GSLs in SCC $(3.57 \mu \mathrm{g} /$ $\mathrm{mg})$ was observed as compared to normal mucosa $(1.92 \mu \mathrm{g} /$ $\mathrm{mg})$. In SCC, an increase of 2 to 3 times in the amounts of $\mathrm{CDH}, \mathrm{CTH}$, Globoside, and GM3 was observed in comparison to normal mucosa. The identification of GM3 as well as its increased expression in SCC was confirmed unequivocally by HPTLC immunostaining and indirect immunofluorescence using MAb DH2 (anti-GM3). BY analyzing SCC and normal mucosa CMHs by GC/MS, normal mucosa expresses only glucosylceramide whereas SCC cells express both glucosylceramide and galactosylceramide. Conclusion: The increase in the amount of GSLs in tumor tissue may represent changes of cell membrane microdomains resulting from the malignant transformation process, which is responsible for greater cell-cell or cell-matrix interaction thereby increasing their potential for infiltration and metastasis.

\footnotetext{
${ }^{1}$ Doutor em Ciências pela Universidade Federal de São Paulo, Ex-pós-graduando do programa de pós-graduação em Otorrinolaringologia e Cirurgia de Cabeça e Pescoço da Universidade Federal de São Paulo. Médico do Serviço de Otorrinolaringologia e Cirurgia de Cabeça e Pescoço da Santa Casa de Misericórdia de Itabuna. ${ }^{2}$ Doutor em Medicina pela Faculdade de Medicina da USP, Médico Assistente da Disciplina de Cabeça e Pescoço da Universidade Federal de São Paulo. ${ }^{3}$ Prof. Titular da Disciplina de Biologia Molecular do Departamento de Bioquímica da Universidade Federal de São Paulo.

Aluna do Curso de Pós-graduação da Disciplina de Biologia Molecular do Departamento de Bioquímica da Universidade Federal de São Paulo.

${ }^{5}$ Aluna do Curso de Pós-graduação da Disciplina de Biologia Molecular do Departamento de Bioquímica da Universidade Federal de São Paulo. ${ }^{6}$ Livre-Docente em Medicina pela Universidade Federal de São Paulo, Chefe da Disciplina de Cirurgia de Cabeça e Pescoço da Universidade Federal de São Paulo. ${ }^{7}$ Profa. Livre-Docente pela Universidade Federal de São Paulo.

Disciplina de Cirurgia de Cabeça e Pescoço e Setor de Imunoquímica de Glicoconjugados da Disciplina de Biologia Molecular do Departamento de Bioquímica da Universidade Federal de São Paulo - Escola Paulista de Medicina (UNIFESP-EPM)

Endereço para correspondência: Marcilio Ferreira Marques Filho - Av. Firmino Alvez 60 sala 205 Centro Itabuna BA $45600-185$. Tel. (0xx73) 3613-0218/ 3613-0424 Cel. (0xx73) 9198-3821 - E-mail: marcilio.marques@terra.com.br FAPESP, CNPq, CAPES.

Este artigo foi submetido no SGP (Sistema de Gestão de Publicações) da RBORL em 12 de agosto de 2005. Artigo aceito em 6 de setembro de 2005 .
} 


\section{INTRODUÇÃO}

Além de delimitar os limites das células, a membrana celular exerce outras importantes funções, sendo responsável pela manutenção do gradiente iônico, pela comunicação com outras células e com o meio externo por meio de receptores transmembrana, localizados em áreas especializadas denominadas de microdomínios ${ }^{2}$. Alterações nos microdomínios e seus componentes, dentre eles os GSLs, estão relacionados ao processo de transformação maligna, tema bastante estudados principalmente em melanoma, carcinoma de mama, cólon e pulmão ${ }^{1}$.

A membrana celular é formada por dupla camada lipídica e proteínas que se dispõem perpendicularmente, atravessando total ou parcialmente os dois folhetos lipídicos ${ }^{2-4}$. A maioria dos lipídios da membrana celular são fosfolipídios. Além dos fosfolipídios, moléculas de colesterol e glicolipídios também são encontradas em grandes quantidades ${ }^{2,5}$ na membrana celular. Os glicoesfingolipídios (GSL) são os glicolipídios mais abundantes na membrana celular, sendo formados por molécula de ceramida (esfingosina ligada a um ácido graxo) com um ou mais resíduos de açúcar ligado ao seu carbono primário ${ }^{5}$, geralmente presentes em áreas especializadas conhecidas como microdomínios ${ }^{2}$. Esses microdomínios, ou lipid raft, são áreas da membrana celular, formadas por GSLs, colesterol e proteínas, funcionando como plataforma onde algumas proteínas se fixam, permitindo atuarem em conjunto e serem transportadas dentro da dupla camada lipídica ${ }^{6,7}$. Importantes funções celulares são atribuídas aos microdomínios, como moduladores da sinalização celular, mediadores da adesão celular e também por funcionarem como antígenos ${ }^{8}$.

Hakomori afirma que os GSLs, dentre eles os gangliosídeos (GSLs com resíduos de ácido siálico), têm a sua expressão aumentada em tumores, devido às alterações em sua glicosilação, observando, ao longo de seus 35 anos de pesquisa, alterações na glicosilação dos GSLs tanto in vitro quanto in vivo ${ }^{1,9}$.

Em melanomas está bem demonstrada a glicosilação aberrante pela expressão do dissialogangliosídeo (GD3), gangliosídeo expresso no melanoma e não no melanócito. Este gangliosídeo está relacionado com crescimento rápido e, principalmente, com a forma indiferenciada e amelanótica do melanoma, funcionando como marcador tumoral ${ }^{10,11}$. Tumores malignos de cólon, mama e pulmão também possuem GSLs como marcadores tumorais, inclusive com pesquisas em fase pré-clinica ${ }^{12,13}$. No melanoma, cujas pesquisas estão em fase mais avançada, já existem vacinas produzidas com anticorpo monoclonal (MAb)l anti-GSLs aprovadas para uso clínico no Canadá e Austrália ${ }^{14}$.

Porém, com relação ao CEC da região da cabeça e pescoço e principalmente do trato aerodigestivo superior existem poucos trabalhos mostrando a expressão de GSLs no processo de transformação maligna ou diferenciação do CEC, apesar de um dos primeiros anticorpos desenvolvidos contra GSLs identificar a LacCer do CEC ${ }^{1,15}$. Somente Bolot et al. (1998, 1999) avaliaram a expressão de GSLs nas células de carcinoma e de tecido normal da região da cabeça e pescoço, porém estes trabalhos deixam dúvidas com relação ao tipo histológico e ao sítio anatômico dos tumores estudados.

Como a expressão de GSLs no CEC é tema pouquíssimo estudado, decidiu-se realizar estudo prospectivo visando avaliar a expressão de GSLs no CEC do trato aerodigestivo superior.

\section{MÉTODO}

Realizou-se estudo prospectivo em 33 amostras de CEC do trato aerodigestivo superior e de mucosa normal desta região de pacientes submetidos a tratamento cirúrgico na disciplina de cirurgia de cabeça e pescoço da UNIFESP-EPM, sendo 15 tumores de laringe, 9 de orofaringe, 3 de hipofaringe e 6 de cavidade bucal. Não foi realizada distinção com relação à idade e ao gênero dos pacientes.

O material coletado foi processado no laboratório de glicoesfingolipídios do Setor de Imunoquímica de Glicoconjugados da Disciplina de Biologia Molecular do Departamento de Bioquímica da Universidade Federal de São Paulo - Escola Paulista de Medicina.

O material foi homogeneizado e os GSLs extraídos com IPA/hexano/ H20 (55:20:25 v/v/v) por duas vezes e uma vez com clorofórmio/metanol $(2: 1 \mathrm{v} / \mathrm{v})$.

Após a extração, os GSLs foram purificados por cromatografia de fase reversa em coluna de C-18 e hidrólise alcalina em metanol16,17. A quantificação dos GSLs foi realizada por densitometria das placas de HPTLC coradas com orcinol utilizando-se densitômetro Shimadzu CS 9000 a $525 \mathrm{~nm}$, tendo como referência o padrão de GM3 (Sigma $\left.{ }^{\circledR}\right)$ na concentração de $0,1 \mu g 17,18$. Para melhor visibilizar os gangliosídeos, as placas foram coradas com resorcinol. Os gangliosídeos foram visibilizados como manchas roxas ${ }^{19}$.

Analisou-se a reatividade dos GSLs expressos ao MAb DH2 (anti-GM3) por imunocoloração das placas de HPTLC e imunofluorescência indireta.

Com os GSLs identificados e quantificados foi realizado o estudo estatístico, empregando-se o teste tindependente, e análise de variância (ANOVA) com nível de significância de 5\%.

Para identificação dos resíduos de açúcar presentes nas moléculas de CMH do CEC e da mucosa normal, o material foi individualizado por HPTLC preparativa e a fração correspondente ao $\mathrm{CMH}$ foi derivatizada (metanólise, re-Nacetilação e trimetilsililação) e analisada em cromatógrafo gasoso CP-3800 acoplados ao espectrômetro de massa Quadrupole MS 1200L Varian® (GC/MS). 
O Comitê de Ética e Pesquisa da Universidade Federal de São Paulo analisou e aprovou a realização deste estudo.

\section{RESULTADOS}

Analisando os dados obtidos, não houve diferença nos tipos de GSLs expressos no CEC em comparação com a mucosa normal, os principais GSLs expressos foram GM3, globosídeo, CTH, CDH e CMH. No entanto, observou-se incremento na expressão dos GSLs no CEC, sendo possível ter idéia dessa diferença analisando-se a intensidade da coloração das bandas de GSLs do CEC em relação a mucosa normal (Figura 1).

Verificou-se aumento significativo na expressão dos GSLs no CEC em comparação à mucosa normal, para esta comparação aplicou-se teste t-independente, onde $\mathrm{p}>0,001$ (Tabela 1).

Para determinar quais os GSLs que se encontram significativamente aumentados no CEC aplicou-se o teste ANOVA. O resultado deste teste estatístico mostrou ser significante para todos os efeitos. Por meio de comparações múltiplas identificou-se que houve maior expressão de todos os GSLs no CEC quando comparado à mucosa normal, exceto para o CMH (Gráfico 1).

Outros gangliosídeos como GM1 e GM2 também foram expressos em algumas amostras de CEC, em quantidades reduzidas.

A reatividade das células do CEC e mucosa do trato aerodigestivo superior ao MAb DH2 (anti-GM3) é demonstrada por imunofluorescência indireta do inprint e por imunocoloração das placas de HPTLC. Nota-se a grande diferença na reatividade do GM3 expresso no CEC quando comparado ao da mucosa normal do trato aerodigestivo superior tanto a imunofluorescência indireta (Figuras 2), quanto à imunocoloração. Não houve reatividade ao MAb MEST-1 (anti $\beta$-galactofuronose), empregado como anticorpo inespecífico, das células do CEC e da mucosa normal.

Os resíduos de açúcar que compõem o CMH foram analisados por meio do GC/MS, comparando-se o tempo de retenção dos padrões de glucose e galactose com os tempos de retenção obtidos do CMH do CEC e da mucosa normal. Detectou-se por GC/MS a presença de dois picos para cada tipo de açúcar, que correspondem aos isômeros a e $\beta$ de cada molécula, com tempo de retenção de 31,325 e 31,977 para a galactose (Gal), e 32,527 e 32,894 para a glucose (Glc). Constatou-se que CEC expressa glucosilceramida (GlcCer) e galactosilceramida (GalCer), enquanto que a mucosa do trato aerodigestivo superior expressa somente glucosilceramida. A GalCer encontrada no CEC representa 35\% das frações de CMH (Figura 3).

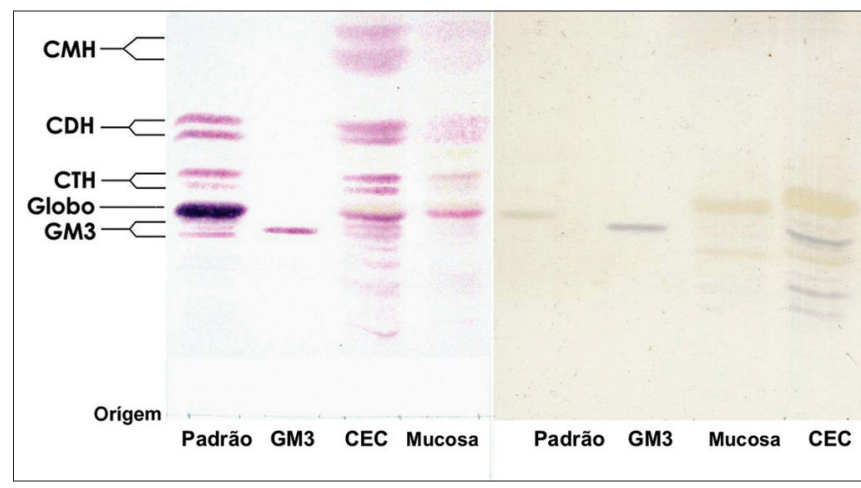

Figura 1. Lâmina de HPTLC corada com orcinol/H2SO4. (esquerda) e (direita) HPTLC corada com resorcino - Padrão - Padrão de GSLs de eritrócitos. GM3 - Padrão de GM3 (Sigma $\left.{ }^{\circledR}\right)$. CEC - GSLs do CEC. Mucosa normal - GSLs da mucosa normal.

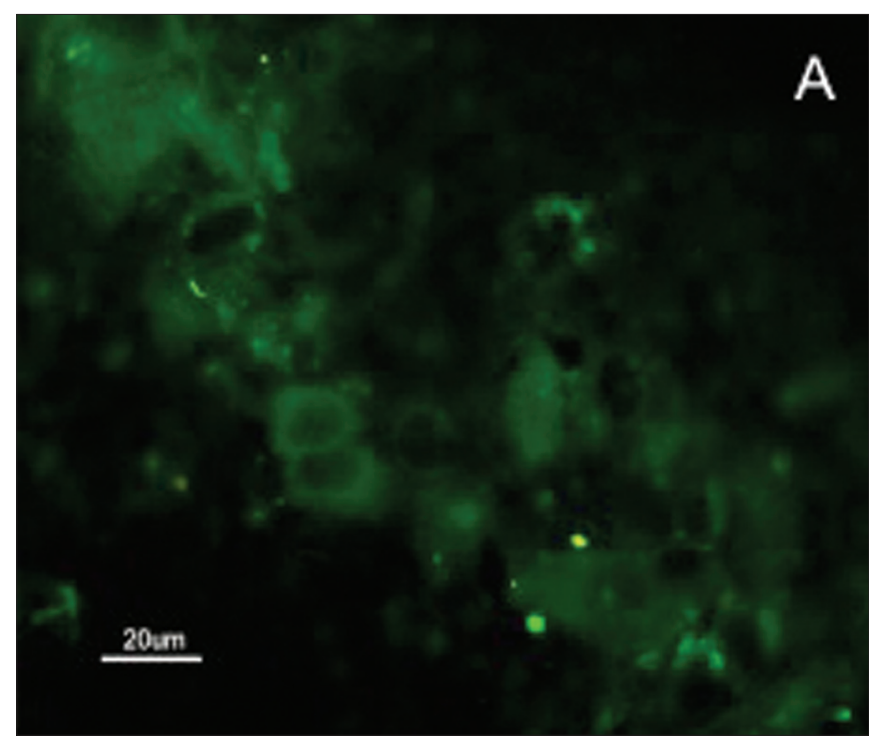

Figura 2. Fotomicrografia de Imunofluorescência indireta onde percebe-se a diferença de reatividade das células de CEC em comparação com as células da mucosa normal ao MoAb DH2 (AntiGM3). - A. células de CEC imunocoradas com DH2 (verde). B. células da mucosa normal marcadas com DH2 (verde). C. núcleo das células de CEC coradas com DAPI (azul). D. núcleo das células da mucosa normal coradas com DAPI (azul).

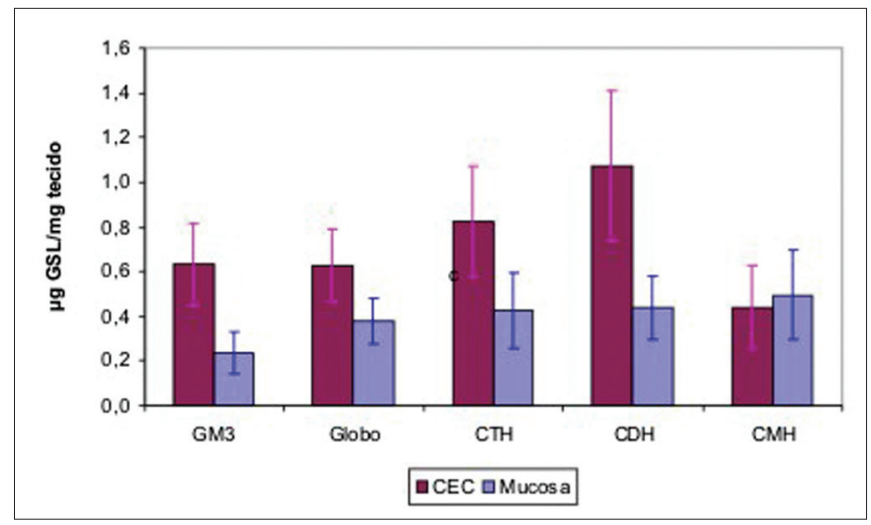

Gráfico 1. Média da quantidade de GSL no CEC e mucosa do trato aerodigestivo superior 


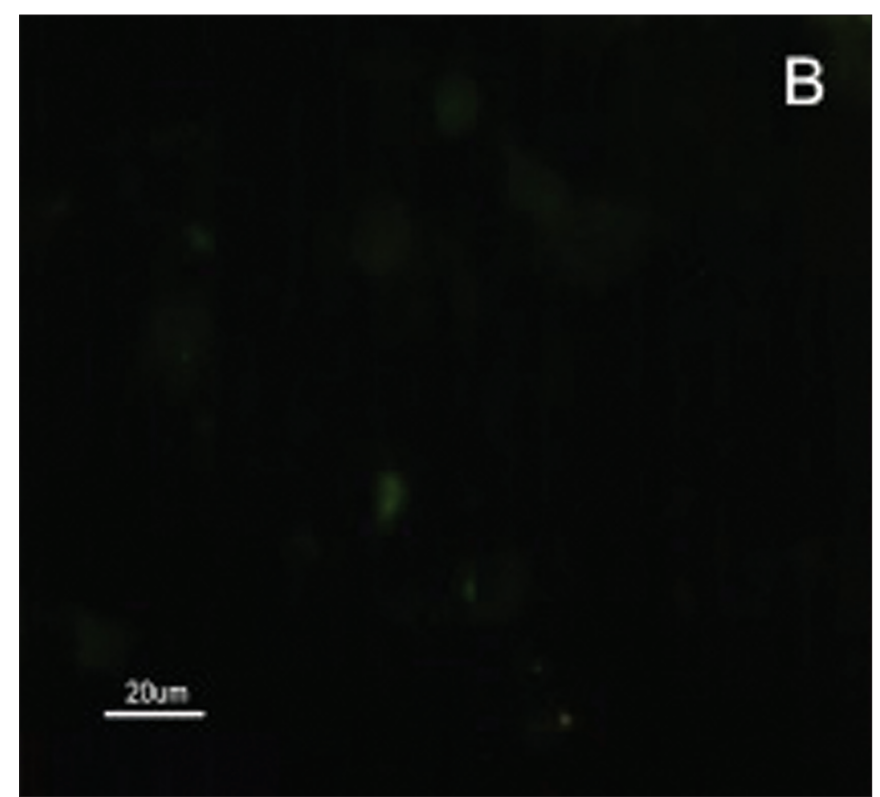

Figura 3. Espectometria de massa das moléculas de CMHs. Os traçados superiores (A e B) mostram a identificação dos resíduos de açúcar da fração do $\mathrm{CMH}$ da mucosa do trato aerodigestivo superior. Os traçados $\mathrm{C}$ e $\mathrm{D}$ correspondem à identificação dos resíduos de açúcar da fração CMH do CEC. Gal - galactose Glc - glucose.

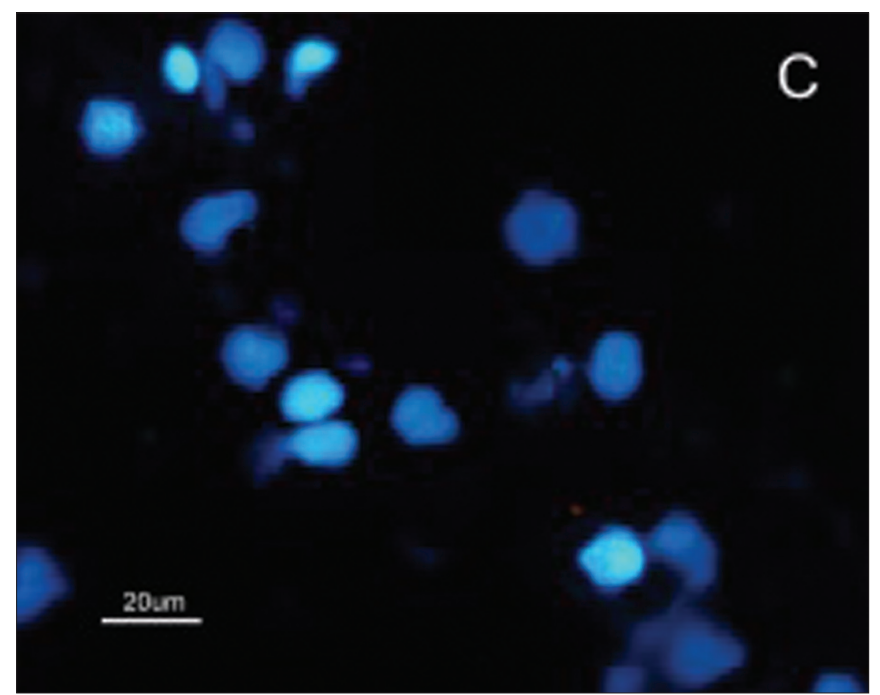

Figura 4. Esquema proposto da via de síntese dos GSLs para explicar o aumento da expressão dessas moléculas no CEC do trato aerodigestivo superior. A maior atividade da lactosilceramida sintase aumentaria a expressão do GM3, CTH e CDH e conseqüentemente reduziria a oferta de Glc para síntese do GlcCer, necessitando as células do CEC utilizar Gal para produzir GalCer e manter a estrutura da membrana celular.

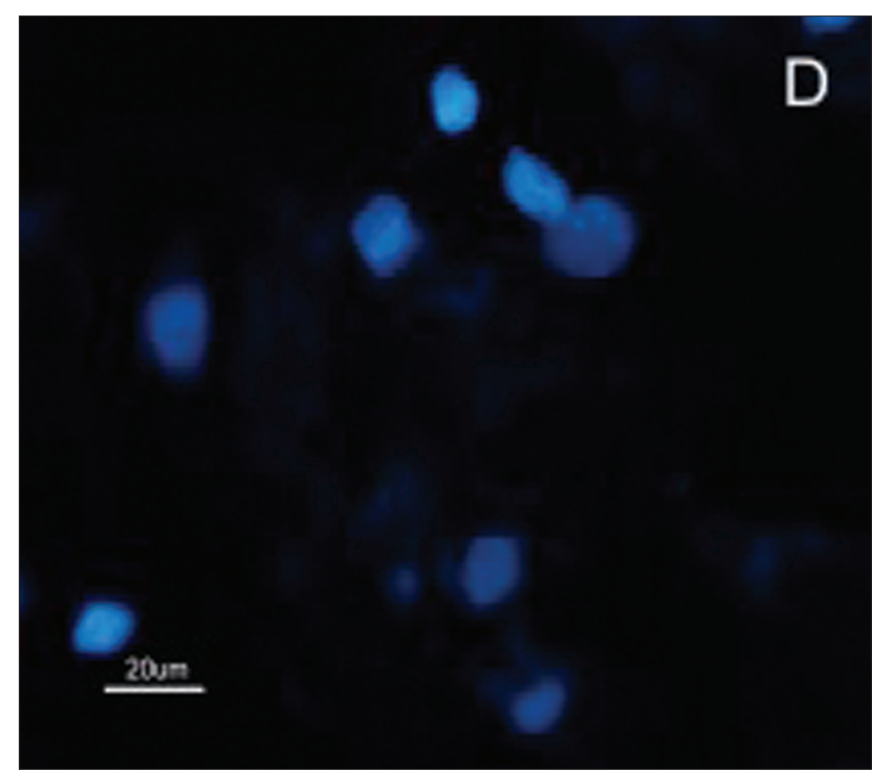

Figura 5. Média da quantidade de GSL no CEC e mucosa do trato aerodigestivo superior.

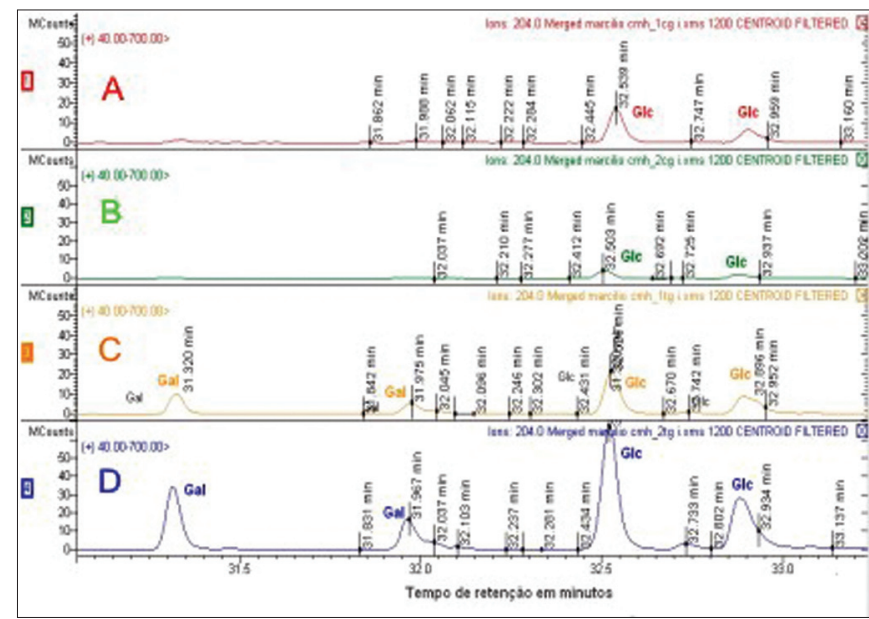

Figura 6. Média da quantidade de GSL no CEC e mucosa do trato aerodigestivo superior.

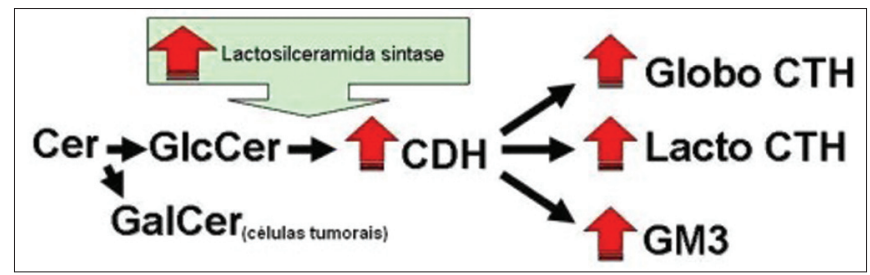

Figura 7. Média da quantidade de GSL no CEC e mucosa do trato aerodigestivo superior. 


\section{DISCUSSÃO}

As alterações na estrutura e expressão dos GSLs no processo de crescimento celular, diferenciação e transformação neoplásica é fato bem demonstrado na literatura, sendo objeto de estudo há décadas ${ }^{9,20}$. Porém, com relação ao CEC da região da cabeça e pescoço e principalmente do trato aerodigestivo superior, existem poucos trabalhos mostrando a expressão de GSLs no processo de transformação maligna ou diferenciação do CEC.

Os dois únicos artigos, de um mesmo grupo, que avaliaram a expressão de GSLs nas células de carcinoma comparando com o tecido normal da região da cabeça e pescoço, deixam dúvidas com relação ao tipo histológico e ao sítio anatômico dos tumores estudados; além disto, o pequeno número de tumores estudados por este grupo, somente seis casos, não representando a expressão de GSLs no CEC de forma inequívoca ${ }^{21,22}$. Outra descrição do perfil de expressão de GSLs no CEC foi realizada ao se estudar a expressão de GSLs durante o processo de diferenciação em linhagem de células de CEC da região retromolar ${ }^{20}$.

Foi observado em nosso trabalho aumento significativo na expressão dos GSLs totais no CEC do trato aerodigestivo superior em relação a mucosa normal, principalmente devido ao aumento na expressão de GM3, globosídeo, CTH e CHD. O CMH é a única exceção, pois se detectou quantidades similares no CEC e na mucosa normal. Analisando os resultados descritos acima e a via metabólica de síntese dos gangliosídeos pode-se supor que a atividade da UDP-Gal: Glucosilceramida $\beta 1$ 4galactosiltrasnferase (lactosilceramida sintase), responsável pela adição de um resíduo de galactose a GlcCer transformando-o em $\mathrm{CDH}$ esteja aumentada devido ao processo de transformação neoplásica. Contribui para esta hipótese o fato de ter sido encontrado na fração de $\mathrm{CMH}$ tumoral GalCer, sugerindo que GalCer estaria sendo sintetizada para a reposição da GlcCer, mantendo desta forma a estrutura da membrana celular (Figura 4).

$\mathrm{O}$ aumento dos GSLs totais e a presença de $\mathrm{CMH}$ na forma de GalCer também foi observado por Bolot et al. $(1998)^{22}$.

Confrontando a expressão de GSLs observados em nosso trabalho com os dados apresentados na literatura, as únicas diferenças encontradas foram a presença de GD3 observada por Tatsumura et al. (1988) e Bolot et al. $(1998)^{20,22}$. E ao analisar a expressão de GSL em coletânea de fragmentos de CEC da região da cabeça e pescoço obtidos de seis pacientes, Bolot et al. (1999) encontraram NAc-GM1 somente no CEC, em quantidades mínimas ${ }^{21}$.

Atribui-se a diferença na expressão dos gangliosídeos por nós verificados em comparação aos descritos por Bolot et al. (1998 e 1999) e Tatsumura et al. (1988), a dois aspectos $^{20-22}$ :
1. Por acreditar ser mais representativo, decidiu-se identificar e quantificar os GSLs em cada fragmento de tecido obtido, ao invés de agrupar vários fragmentos de tecido e analisá-los de forma única, como realizado por Bolot et al. (1998 e 1999), ou do estudo de Tatsumura et al. (1988) que empregaram linhagem de células de $\mathrm{CEC}^{20-22}$.

2. Pode realmente haver diferença na expressão dos GSLs, pois são bem demonstradas na literatura as grandes diferenças existentes tanto no genótipo quanto no fenótipo do CEC, fato que impossibilitou até os dias de hoje estabelecer marcadores tumorais confiáveis para uso clínico no CEC $23-25$.

Chama atenção nos trabalhos de Bolot et al. (1998 e 1999), a quantidade de GD3, semelhante a do GM3, o que reforça a hipótese de padrão distinto na expressão de GSLs nos tumores estudados por estes autores, em relação à amostras analisadas em nosso estudo ${ }^{21,22}$.

Tatsumura et al. (1988) observaram em linhagem de células de CEC (SqCC/Y1) cultivadas em meio de cultura completo a expressão de GD3 reduzida. Somente com o cultivo das células SqCC/Y1 em meio de cultura sem soro foi detectado aumento significativo da expressão de GD3.

É curioso observar aumento do GM3 em tecidos tumorais, pois o seu aumento está associado à inibição do processo de crescimento celular. O GM3 inibe a autofosforilação dos receptores dos fatores de crescimento epitelial26,27, e pode induzir a apoptose via Bcl-29. Outra hipótese, contrariando a explicação anterior, é possibilidade do GM3 atuar como um segundo mensageiro do processo de regulação do crescimento celular, no entanto, são ainda necessários estudos mais detalhados para comprovar o papel do GM3 no crescimento celular ${ }^{27}$.

A principal possibilidade de emprego dos GSLs para auxiliar no diagnóstico e tratamento de neoplasias malignas baseia-se na alteração da estrutura e/ou conformação dos GSLs, mais precisamente dos resíduos de carboidratos dessas moléculas, possibilitando a produção de MAb que reconhecem especificamente GSLs associados a tumores.

No presente estudo, por haver expressão de GM3 tanto na mucosa quanto no CEC seria esperado uma reatividade ao MAb DH2 proporcional à concentração desse GSLs em ambos os tecidos, porem isso não foi observado (Figuras 2). Acredita-se que a diferença na reatividade do GM3 justifica-se pela sua disposição conformacional nos microdomínios quando expresso em maior quantidade. Sabe-se, por exemplo, que o MAb M2590 (anti-GM3) somente detecta GM3 em células onde ocorre grande expressão de GSLs, e existe a tendência desse glicoconjugado em agrupar-se de forma distinta nos microdomínios quando ocorre aumento de sua expressão, aumentando desta forma, a reatividade ao MAb M2590. Estes resultados sugerem a necessidade de concentração crítica para uma 
interação ótima com MAb DH2.28

Como mencionado anteriormente ocorre aumento da expressão do GM3 no crescimento celular, experimentalmente, observou-se o efeito inibitório de DH2 (antiGM3) no crescimento de células de melanoma in vivo e in vitro $^{29}$. Por outro lado verificou-se que ao adicionar GM3 em meio de cultura, ocorria uma inibição do crescimento celular. Esses resultados contribuíram para o desenvolvimento de pesquisas experimentais e clínicas procurando empregar GSLs e mAbs (anti-GSL) no diagnóstico e tratamento de neoplasias malignas ${ }^{1}$. Como resultado, foram produzidos mAbs especificamente dirigidos contra GSLs e associados a diferentes tumores. Esses mAbs dirigidos a GSLs associados a células tumorais têm sido utilizados em exames citológicos e anatomopatológicos procurando diferenciar lesões benignas de tumores malignos ${ }^{17}$. Apesar de promissores, até o momento, o uso clínico dos GSLs no diagnóstico e tratamento do câncer ainda é restrito a alguns tipos de tumores, como o melanoma ${ }^{9,30,31}$.

O emprego de GSLs como antígeno ${ }^{2}$ em vacinas anticâncer é uma possibilidade que tem despertado interesse da comunidade científica nos dias atuais. Em um estudo fase III, onde se empregou antígenos associados a carcinoma de pulmão, obteve-se uma sobrevida de 70\% contra 49\% para estádios I e II em 5 anos ${ }^{32}$. O maior número de vacinas anticâncer foram desenvolvidas e testadas contra células de melanoma, utilizando-se de mAbs anti-GM3, GM2 e GD3. Outras vacinas foram produzidas contra tumores como, por exemplo, de mama e de intestino, porém, permanecem como ensaios clínicos.

Somente no Canadá e Austrália existem vacinas anticâncer para melanoma aprovadas para uso clínico, onde pacientes já com metástase tiveram um aumento de sobrevida de $25 \%$ para 50\% em cinco anos. Apesar desses resultados promissores, a maioria das vacinas anticâncer desenvolvidas até hoje permanecem como pesquisa, não sendo aprovadas pelas agências reguladoras norte-americana (FDA) e européia para uso clínico ${ }^{14}$.

Portanto, as possibilidade de emprego dos GSLs e de MAb que reconheçam estes GSLs para auxiliar no diagnóstico e no tratamento do CEC é promissora, a exemplo do melanoma, no entanto, são necessários trabalhos estruturais e imunoquímicos de GSLs no CEC, bem como nos diversos tumores que acometem a região da cabeça e pescoço.

\section{CONCLUSÃO}

Os resultados deste trabalho permitem concluir que existe um significativo aumento na expressão de GSLs no CEC do trato aerodigestivo superior quando comparado com a mucosa normal da mesma região. Esse aumento de expressão ocorre principalmente em GM3, globosídeo, CTH, CDH e a hipótese principal da maior expressão em processos de transformação maligna estaria relacionada a aumento na quantidade e atividade da Lactosilceramida sintase.

\section{REFERÊNCIAS BIBLIOGRÁFICAS}

1. Hakomori S. Aberrant glycosylation in tumors and tumor-associated carbohydrate antigens. Adv Cancer Res 1989; 52: 257-331.

2. Tamm LK, Kiessling V, Wagner ML. Membrane Dynamics. Encyclopedia of Life Sciences. Macmillian Publishers Nature; 2002.

3. Singer SJ, Nicholson GL. The structure and chemistry of mammalian cell membranes. Am J Pathol 1971; 65(2): 427-37.

4. Singer SJ, Nicholson GL. The fluid mosaic model of the structure of cell membranes. Science 1972; 175(23): 720-31.

5. Hakomori S, Ishizuka, I. Glicolipids: Animal. Encylopedia of Life Sciences; 2002: 1-17.

6. Simons K, Ikonen E. Functional raft in cell membranes. Nature 1997; 387: 569-72.

7. Toledo MS et al. Cell Growth Regulation through GM3-enriched Microdomain (Glycosynapse) in Human Lung Embryonal Fibroblast WI38 and Its Oncogenic Transformant VA13. J Biological Chemistry 2004; 279(33): 34655-64

8. Hakomori S. Structure Organization and function of glycosphingolipids in membrane. Curreunt Opinion in Hematology 2003; 10: 16-24.

9. Hakomori S. Glycosylation definig cancer malignacy: New wine in an old bottle. PNAS 2002; 99(16): 10231-3.

10. Duarte APM. Papel de dissialogangliosídeos na progressão tumoral de melanomas. In: Oncologia 2004; Fundação Antônio Prudente: São Paulo. p. 135.

11. Birkle $\mathrm{S}$ et al. Down-regulation of GD3 ganglioside and its Oacetylated derivative by stable transfection with antisense vector aginst GD3-synthase gene expression in hamster melanoma cells: effects on cellular growth melanogenesis and dendricity. J Neurochem 2000; 74 .

12. Itzkowitz SH et al. Expression of Tn Sialosyl-Tn and T Antigens in Human Colon Cancer. Cancer Research 1989; 49: 197-204.

13. Fernandez LE et al. Ganglioside-based vaccines and anti-idiotype antibodies for active immunotherapy against cancer. Expert Rev Vaccines 2003; 2(6): 817-23.

14. Bitton RJ et al. Cancer vaccines: An update with special focus on ganglioside antigens (Review). Oncology Reports 2002; 9(2): 267-76.

15. Rapport MM et al. Immunochemical studies of organ and tumor lipids. VI. Isolation and properties of cytolipin H. Cancer 1959; 12(3): 438-45.

16. Becker GW, Lester RL. Biosynthesis of Phosphoinositol-Containing Sphingolipids from Phosphatidylinositol by a Membrane Preparation from Saccharomyces cerevisiae. J Bacteriology 1980; 142(3): 747-54.

17. Nakakuma $\mathrm{H}$ et al. Common Phenotypic Expression of Gangliosidies GM3 and GD3 in Normal Human Tissues and Neoplastic Skin Lesions. Jpn J Clin Oncol 1992; 22(5): 308-12.

18. Toledo MS et al. Glycolipids from Paracoccidioides brasiliensis Isolation of a galactofuranose-containing glycolipid reactive with sera of patients with paracoccidioidomycosis. Journal of Medical and Veterinary Mycology 1995; 33: 247-51.

19. Carvalho RSH et al. Highly-substituted benzhydrylamine resin: An alternative chromatographic support for ganglioside and neutral glycosphingolip purification. Chromatographia 2000; 52: 363-6.

20. Tatsumura $\mathrm{T}$ et al. Changes in Glycosphynolipids accompanying the differentiation of human squamous SQCC/Y1 cell. Cancer Res 1988; 48(8): 2121-4.

21. Bolot $\mathrm{G}$ et al. Occurrence of monosialosyl pentahexaosylceramide GalNAc-GM1 as specific tumor-associated ganglioside of human head and neck squamous cell carcinomas. Cancer Lett 1999; 135(2): 159-64.

22. Bolot $\mathrm{G}$ et al. Analysis of glycosphingolipids of human head and neck carcinomas with comparison to normal tissue. Biochem Mol 
Biol Int 1998; 46(1): 125-35.

23. Scully C, Field JK, Tanzawa H. Genetic Aberration in Oral or Head and Neck Squamous Cell Carcinoma (SCCHN)1: Carcinogen metabolism DNA repair and cell cycle control. Oral Oncology 2000. 36: $256-63$

24. Scully C, Field JK, Tanzawa H. Genetic Aberration in Oral or Head and Neck Squamous Cell Carcinoma (SCCHN)2: Cromossomal Aberrations. Oral Oncology 2000. 36: 311-27.

25. Scully C, Field JK, Tanzawa H. Genetic Aberration in Oral or Head and Neck Squamous Cell Carcinoma (SCCHN)3: Clinico-pathological applications. Oral Oncology 2000. 36: 404-13.

26. Song W et al. Effects of Gangliosides GM3 and De-N-acetyl GM3 on Epidermal Growth Factor Receptor Kinase Activity and Cell Growth. J Biol Chem 1991; 266(16): 10174-81.

27. Zohou Q et al. GM3 Direct Inhibits Tyrosine Phosphorylation and De-N-acetyl-GM3 Directly Enhances Serine Phosphorylation of Epi- dermal Growth Factor Receptor Independently of Receptor-Receptor Interaction. J Biol Chem 1994; 269(3): 1959-65.

28. Nores GA et al. Density-dependent recognition of cell surface GM3 by a certain anti-melanoma antibody and GM3 lactone as a possible immunogen: requirements for tumor-associated antigen and immunogen. J Immunol 1987; 139(9): 3171-6.

29. Dohi TG, Nores, Hakomori S. An IgG3 Monoclonal Antibody Established after Immunization with GM3 Lactone: Immunochemical Specificity and Inhibition of Melanoma Cell Growth in Vitro and in Vivo. Cancer Res 1988; 48(8): 5680-5.

30. Alfonso M, Zeuthen J. Generation of human monoclonal antibodies against ganglioside antigens and their applications in the diagnosis and therapy of cancer. Acta Oncol 1996; 35(3): 287-95.

31. Muthing $J$ et al. Preferential binding of the anticancer drug rViscumin (recombinant mistletoe lectin) to terminally alpha2-6-sialylated neolacto-series gangliosides. Glycobiology 2002; 12(8): 485-97. 


\section{ERRATA}

VOLUME 72 EDIÇÃO 1 - Jan/Fev 2006

Expressão de glicoesfingolipídeos no carcinoma espinocelular do trato aerodigestivo superior

Glycosphingolipid expression in squamous cell carcinoma of the upper aerodigestive tract

Marcilio Ferreira Marques Filho $\bullet$ Fernando Walder

- Helio K. Takahashi • Luciana L. Guimarães • Ameria K.

Tanaka • Onivaldo Cervantes • Anita H. Straus

Correção das legendas das imagens

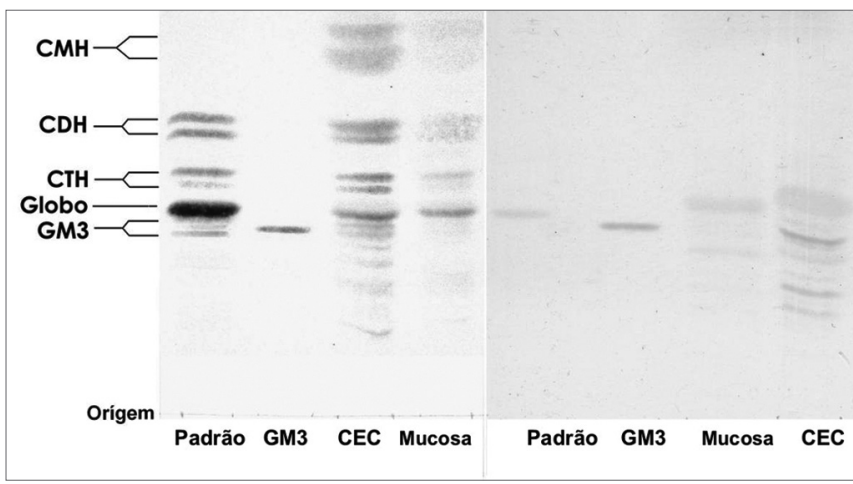

Figura 1. Lâmina de HPTLC corada com orcinol/H2SO4. (esquerda) e (direita) HPTLC corada com resorcinol. Padrão - Padrão de GSLs de eritrócitos. GM3 - Padrão de GM3 (Sigma $\left.{ }^{\circledR}\right)$. CEC - GSLs do CEC. Mucosa - GSLs da mucosa normal.

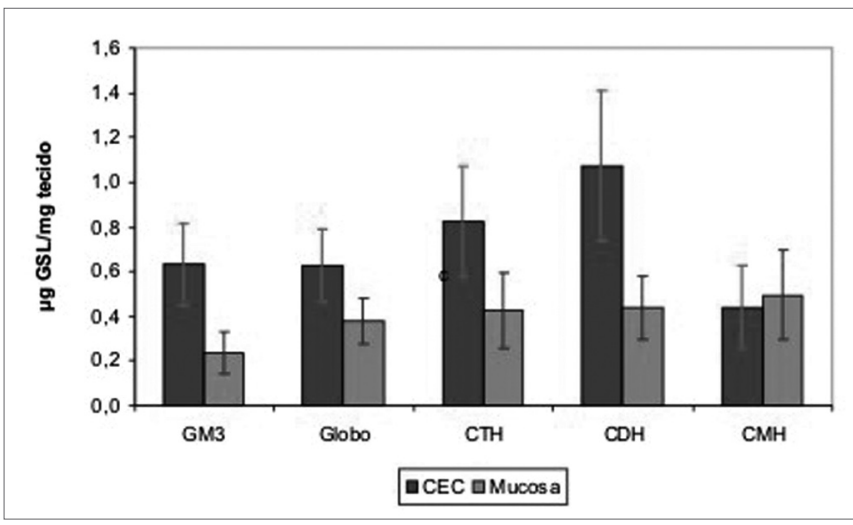

Gráfico 1. Média da quantidade de GSL no CEC e mucosa do trato aerodigestivo superior

Tabela 1. Relação entre as quantidades médias de GSL totais no CEC em relação a mucosa normal do trato aerodigestivo superior

\begin{tabular}{cccc}
\hline Estatísticas & $\begin{array}{c}\mathrm{CEC} \\
\mu \mathrm{g} \mathrm{GSL} / \mathrm{mg} \\
\text { Tecido }\end{array}$ & $\begin{array}{c}\text { Mucosa } \\
\mu \mathrm{g} \mathrm{GSL} / \mathrm{mg} \\
\text { Tecido }\end{array}$ & Teste t $(\mathrm{p})$ \\
\hline Média & 3,57 & 1,92 & \\
Desvio-padrão & 2,35 & 1,54 & 0,001 * \\
$\mathrm{n}$ & 33 & 33 & \\
\hline
\end{tabular}

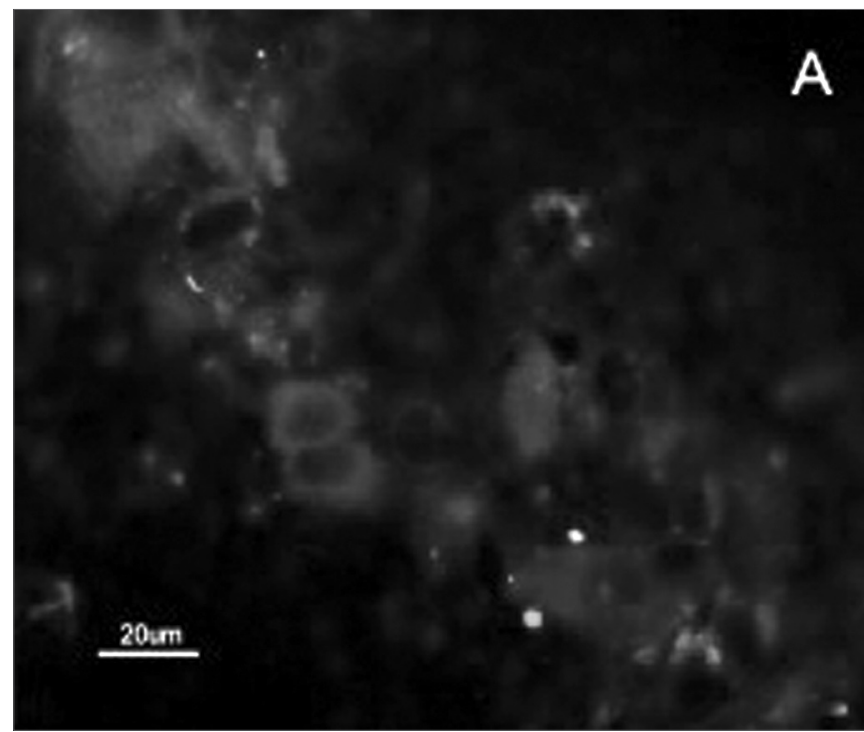

\section{Figura 2a.}

\section{Figura 2b.}

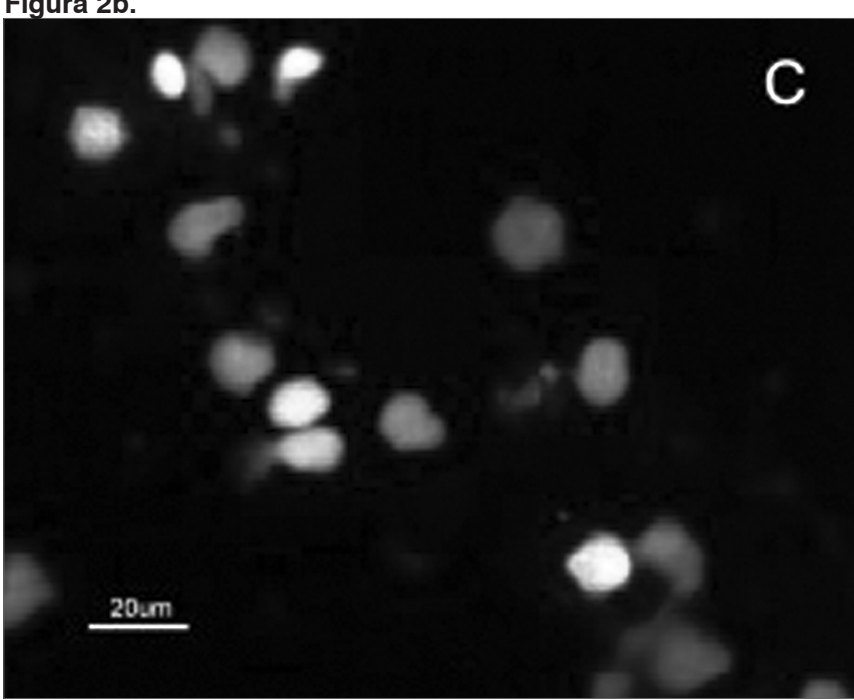

\section{Figura 2c.}




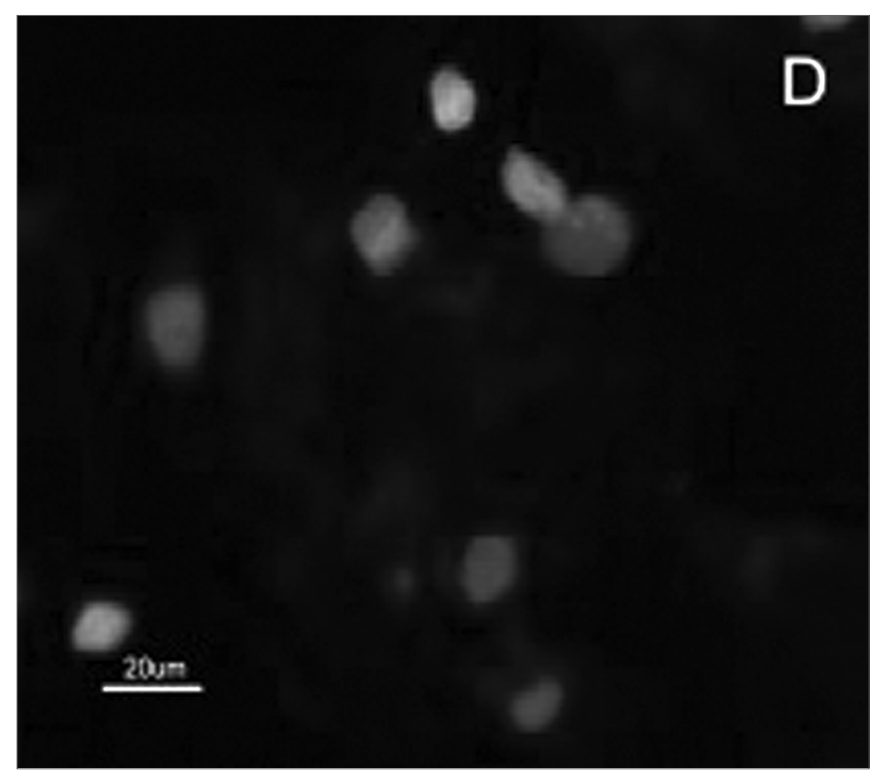

Figura 2d.

Figura 2. Fotomicrografia de imunofluorecencia indireta onde percebese a diferença de reatividade das células de CEC em comparação com as células da mucosa normal ao MoAb DH2 (AntiGM3).

A. células de CEC imunocoradas com DH2 (verde).

B. células da mucosa normal marcadas com DH2 (verde).

C. núcleo das células de CEC coradas com DAPI (azul).

D. núcleo das células da mucosa normal coradas com DAPI (azul).

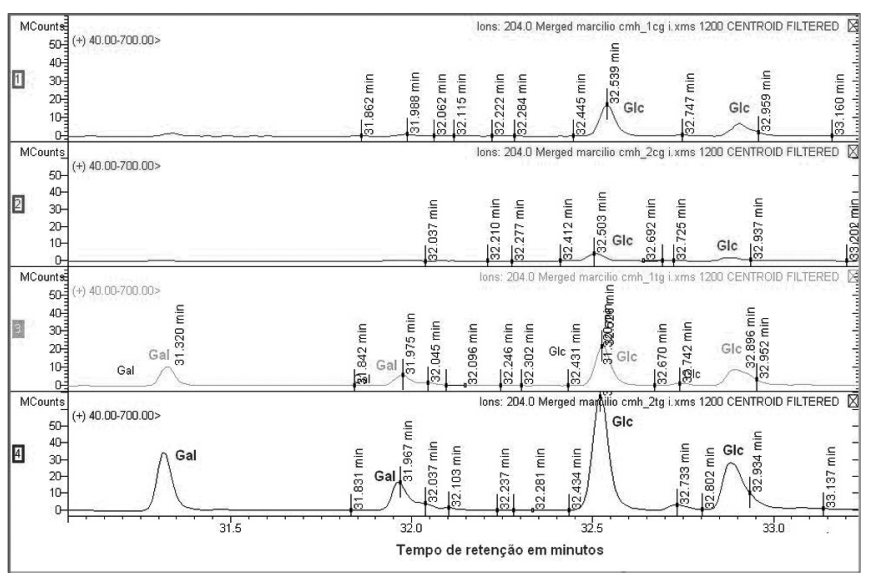

Figura 3. Espectometria de massa dos $\mathrm{CMHs}$.

Os traçados superiores ( $\mathrm{A}$ e B) mostram a identificação dos resíduos de açúcar da fração do $\mathrm{CMH}$ da mucosa do trato aerodigestivo superior. Os traçados $\mathrm{C}$ e D correspondem a identificação dos resíduos de açúcar da fração CMH do CEC.

Gal - galactose, Glc - glucose

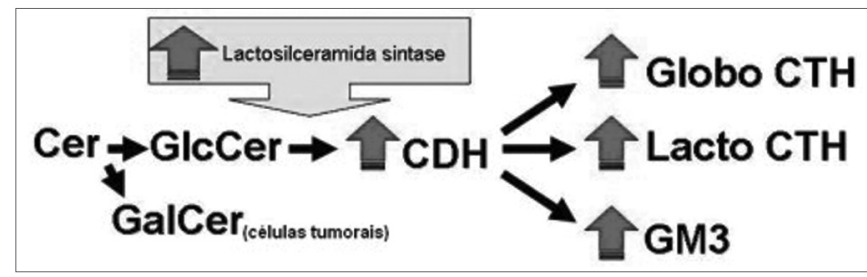

Figura 4. Esquema proposto da via de síntese dos gangliosídeos para explicar o aumento da expressão de GSLs no CEC do trato aerodigestivo superior. A maior atividade da lactosilceramida sintase aumentaria a expressão do GM3, CTH e CDH e consequentemente reduziria a oferta de Glc para síntese do GlcCer necessitando as células do CEC utilizar Gal para produzir GalCer e manter a estrutura da membrana celular. 
O arquivo disponível sofreu correções conforme ERRATA publicada no Volume 72 Número 5 da revista. 